\title{
On the Exploration of the Educational Function of College Students' Volunteer Service Activities
}

\author{
Lian-song $\mathrm{Wu}^{1}$, Hong-lian Liu ${ }^{2}$ \\ ${ }^{1}$ School of Foreign Studies, Yangtze University, Jingzhou, Hubei, China (wls@ yangtzeu.edu.cn) \\ ${ }^{2}$ Jingzhou Experimental Middle School, Jingzhou, Hubei, China (lotuswilliam@vip.qq.com)
}

\begin{abstract}
As an indispensable part of civilized society, volunteer service owns the characteristics of gratuitousness, voluntary, public-welfare and practice. It is a noble social behavior and an important social welfare undertaking, and the educational value of which should not be underestimated at any circumstances. Colleges and society should strengthen the education and guidance of volunteer service, create atmosphere and cultivate voluntary consciousness, make constant innovation of contents and forms of volunteer service, and improve its incentive mechanism, to establish a long-term mechanism of college students' volunteer service.
\end{abstract}

Index Terms-Volunteer Service, College Students, Educational Function

As the embodiment of Chinese traditional virtues, Volunteer service is the vivid practice of socialist morality. In recent twenty years, with the development of the times and social progress, especially the rapid development of socialist market economy, the influence of volunteer service in the contemporary China is increasingly extensive and profound. It is universally acknowledged that Volunteer service has been playing a vital important role among social practice activities of college students. It is the main and important way to realize the self-education of them, and also an effective carrier of Ideological and political education in Universities under the new situation, which plays a positive role in promoting the healthy growth of College students.

\section{The Conception and Features of College Students' Volunteer Service}

\section{A. The Conception of Volunteer Service}

Voluntary service originated from religious charitable services in western countries at the beginning of nineteenth Century. Although the spirit of volunteerism had spread to China for a long time, the concept of voluntary service in China officially has been proposed for the first time in 1994, when the China Youth Volunteer Association of has been established. And now, China Youth Volunteers Action has been through 21 years. With the rapid development of human society, the content of volunteer service has been constantly enriched. As the Second article of China Youth Volunteer Service Regulations proposed, voluntary service refers to volunteer to serve others and social voluntarily and freely. Volunteer service has become one of the standards to the mature civil society, and also has become one of the indispensable elements in the modern society.

College students' volunteer service is a body defined by the scope of the students group, and mainly means the behavior that college students spend their spare time to provide their own service. With distinctive characteristics of the times, volunteer service activities are one of the most important ways of social practice and participation in social activities for the college students, which is developed professionally with the trend of project branding. In view of the types of volunteer service in China, it can be summarized as follows: participation in poverty alleviation and development, participation in community construction, participation in environmental protection, participation in large-scale activities, participation in social welfare undertakings, participation in western volunteer service plan and participation in international voluntary service.

\section{B. Characteristics of Volunteer Service}

1) Gratuitousness. The participation of volunteers' service is a completely unselfish behavior. When participating in volunteer service activities, volunteers take dedication to social service and others as their own social responsibility and obligation. They spend personal time, skill, intelligence, free of charge, to practice core social values with the core of love and mutual aid, and achieve their value in dedication to the society. As Annan, the former Secretary-General of United Nations, said, "The core of the volunteer spirit is the ideal of service and unity, which make the world a glorious place commonly."

2) Voluntary. Rather than from the compulsory or some external force, volunteer service is a volunteer volunteering service for their own wishes, or providing services from subjective conscious. It is the freedom of choice and reflects the will of the individual autonomous behavior, which is so-called "provide as much as I can". The purity of the volunteer motivation and the height of the freedom of the will embody the active pursuit of life. It is also the powerful spiritual force based in the active life and the concept of social individual to fulfill the social responsibility, which is a way for pursuing the lofty of life.

3) Public-welfare. Volunteer service takes social welfare as the starting point, advocates the sacrifice and altruism, the gist of which is providing service for the improvement and promotion for the social progress and for the public and social public welfare activities. The object of the volunteer service is the other people and society, and the content is to protect the public interests or the interests of vulnerable groups. Public-welfare and altruism are the most outstanding volunteer service performance of moral value. At present, the embodiment of public-welfare of volunteer service exists in helping the weak and disabled, emergency rescue and disaster relief, a great match and other large social commonweal activity field.

4) Practice. In the volunteer process, volunteers establish the benign interaction with the society. On the one hand, in the implementation of voluntary service activities, 
volunteers can apply theoretical knowledge in practice, and constantly test their understanding of society in the process of solving practical problems; on the other hand, knowledge which had been tested by practice is more close to the actual, and is helpful to the further enhance of the ability and level of volunteers, which could provide better service for others and the society. Throughout the carrier of volunteer service, the volunteer could transform their subjective world in the transformation of the objective world, and complete the process of dialectical development from recognition to practice and then return to the recognition, thus realize the organic combination of theory with practice.

\section{The Value of Volunteer Service in Educational Field of the University}

As a noble social behavior and important social welfare undertakings, the government of China gives top priority to volunteer service seriously. Xi Jinping, The general secretary of Communist Party of China made important instructions to the youth volunteer work for several times, and points out that the youth volunteer service is a noble cause. University volunteers' service advocates the spirit of volunteerism, i.e. dedication, friendship, mutual aid, and making progress. Throughout various forms to encourage college students to participate in school inside and outside activities and public service, university volunteers' service grasp the trend of the times, expand the service space, enrich the content of services, activate the service thinking, which reflects the spirit and the characteristics of the times. The volunteer service has become a vast arena for students to understand the society, a fiery furnace to temper their mind and talent. In a word, the value of volunteer service in the educational field in colleges and universities can be mainly concluded in the following aspects:

\section{A. To Promote the Formation of Correct Worldview, outlook on Life and Values for College Students}

The period of university life is the crucial stage for the formation of the world outlook, outlook on life, viewpoint of values of college students. In the social background of money worship, hedonism and individualism and other negative effects magnified, college students' value system is experiencing a huge test. Give roses, hand there are lingering fragrance. Volunteer service is also significant in this means. It is the "help", is also "self-help", is "making people happy", also "making oneself happy". Volunteer service enable students truly combine ideological self-cultivation theory of the course with the practice process. Also, long-term volunteer services can help them to formulate moral awareness and generate huge influence in guiding their ideological values.

\section{B. To Strengthen the Social Responsibility of College Students}

Social responsibility is not only the obligations of every citizen to society, but also the precious quality of contemporary college students. In the social background of economic globalization and the ideological pluralism, the sense of social responsibility of college students will affect the development of the socialist cause directly. Voluntary service provides the opportunity to participation in social activities and understanding of society for college students. Dedication to the public can enhance college students' consciousness of the society, and is crucial to the cultivation of the personality quality of responsibility to the family and the society. At the same time, when voluntary service they provided to the society is generally recognized and appreciated by the society, students are more aware of their importance to the others and the society, so as to encourage the promotion college students' social responsibility.

\section{To Enrich the Cultural Life of College Students}

At present, various forms of volunteer service activities of undergraduates in colleges and universities not only broaden the students' living space, enrich their spiritual and cultural life, but also become one of the beautiful scenery lines in university campus. Taking dedication to the society as the excellent moral character, volunteer promote new upright, spread the social mainstream value, and establish a distinctive moral benchmarking, which produce a positive energy to promote the development and progress of campus culture. When spread civilization in the transmission of providing service of others and the society, volunteer service activities pose a positive impact and radiation effects on the surrounding students, which can arouse the feelings of love on campus and the pursuit of the true, the good and the beautiful. It also can stimulate students' enthusiasm and initiative to participate in the construction of campus culture, and is propitious to the formation of the positive campus culture, which can enrich students' spiritual and cultural life, and promote the development of harmonious campus.

\section{To Improve the Comprehensive Qualities of College Students}

Training the talents to meet the needs of the society is the main task of colleges and universities. College education should not only help students increase their knowledge, skills, and is the important resource for students' personality perfection and development. Adapting their knowledge and skills in providing services for others and the society, volunteer service contribute to the stimulation of learning motivation of students, and improve their level of knowledge and the ability of social practice. When participating in volunteer service organization management, dealing with all kinds of complicated problems, some abilities such as organization coordinated ability, language expression ability and self-control ability can be improved on a large extent. Through volunteer service activities into social practice, students can be soberly aware of the needs and expectations of the society, and more deeply aware of their mission, as a result, to stimulate the formation of attitude of enthusiastic to life. On the other hand, the training and the process of voluntary service will promote students' team consciousness, responsibility consciousness; practical ability and problem solving ability have been enhanced greatly. For example, college students who engaged in the Beijing Olympic Games volunteer service are welcomed to the employer particularly.

\section{Countermeasures and Suggestions for Strengthening the Educational Function of College Students' Volunteer Service}
A. To Strengthen the Education and Guidance, Create Atmosphere for Voluntary Service and Cultivate Voluntary Service Consciousness
1) Strengthening the propaganda and guidance, and 
vigorously create atmosphere for volunteer service. We should give full play to the role of campus network publicity, publicity column, newspaper magazine and other campus media. Through the comprehensive propaganda of activities and the spirit of volunteer service, colleges could establish some voluntary service models, and carry forward the spirit of volunteerism, create a strong atmosphere of the campus volunteer service, thus attract more students to join the volunteer service. Colleges should actively seek the support of relevant government departments; further broaden the channels for publicity, and the role of newspapers, radio and television, the Internet and other social media. Through the spreading of the volunteer spirit and relevant knowledge, colleges can attract the masses concerned and promote the public perception and acceptance of voluntary service, and create a good atmosphere for volunteer service finally.

2) Strengthening education and guidance, and develop volunteer service consciousness. As an effective carrier of education practice, volunteer service provides a practice platform for displaying of talent and promoting moral emotion for the majority of students. It plays a crucial role in cultivating students' sense of social responsibility and the spirit of innovation and practical ability education. Therefore, colleges should strengthen the education to cultivate college students volunteer service consciousness, and promote their voluntary consciously participation in volunteer service activities. Otherwise, colleges should take cultivating volunteer spirit as the important content to strengthen and improve the college students' Ideological and political education. League organizations at all levels should select some advanced and typical students to help others understand the connotation, the significance and role of volunteer service, then stimulate their enthusiasm into internalized conscious behavior, and provide sound ideological guarantee for regular, persistence of volunteer service activities.

\section{B. To Keep Pace with the Times, Make Constant Innovation of Contents and Forms of College Students' Volunteer Service}

1) Work should be based on the center work and the requirements of social development. We should continuously enhance the actual effect of college students' volunteer service work. To keep pace with the times, we should continuously expand the space of practice, and make creative methods of this work. In volunteer service activities, some daily activities such as: compulsory labor, beautification and greening the campus and other activities, can be carried out. Also, activities can be based on the political development, such as: "one to one" assistance, and caring children of migrant workers. At the same time, resources can be further integrated, and establish some long-term brand items, such as: social practice base, summer social practice and college students into the community activities. By doing these, we could give full play to the positive role of various voluntary services.

2) Online volunteer service should be enhanced. Adhering to the spirit of Lei Feng, network of volunteer service provides a new way to help others, which is a new trend of the development of China's voluntary service. The network of volunteer service has gradually become the way of the pursuit of college students. It realizes the organic unity of volunteer service integrating the virtual network with real practice. Based on their actual situation, colleges and universities can realize their recruiting effectively to carry out extensive online volunteer service.

\section{To Exert the Main Role of the Colleges and Improve the Incentive Mechanism of College Students' Volunteer Service}

Nowadays, college students' volunteer service motivation channels are not wide enough. Based on the reality of the college, colleges and universities can carry out according to the rule of China Youth Volunteer Registration Management Measures (Trial), made by Chinese Young Volunteers Association, constantly improve the safeguard mechanism of volunteer service, safeguard comprehensively the legitimate rights and interests of college students volunteers, relieve their worries, and further promote and protect college students volunteer service deeply and extensively.

1) A volunteer star-certification recognition system to improve the incentive mechanism of volunteer should be established. New media can be used to transmit voluntary culture. Volunteer oath can be further carried out in the process of register and oath. We should work hard to the promotion of the use of volunteer identity, and enhance the effect of the brand of volunteers. Extensive typical characters and typical deeds of volunteer work should be discovered to promote the constant development of voluntary service.

2) Volunteer service's training security system should be improved to promote the information process of voluntary service work. So as to promote the construction of long-term mechanism of college students' volunteer service, scientific mobilization mechanism should be established, intercollegiate cooperation mechanism should be strengthened, and some cooperation mechanisms between college students' volunteer service and social organization should be standardize gradually.

\section{Conclusion}

Nowadays, college students' volunteer service work is showing a booming trend, and has been arranged into the daily education program in most colleges and universities. It has been proved by the practice that volunteer services provide a good platform for the development of the college students in the way of stimulating students' sense of ownership, enhancing their sense of social responsibility, at the same time trained perseveringly volunteer spirit. Although volunteer service in China is still in the stage of development and some problems are inevitably exist, as long as guiding by correct direction, and constantly improve the level of organization construction, strengthen the management and improve the operation mechanism, the prospect of college students volunteer service is bound to a brilliant.

\section{References}

[1] Xiao Hailing, The role play and its countermeasures of the function of ideological and political education of volunteer service activities, Wuhan: Central China normal university, 2012.

[2] Dou Xiankun, ZhuXiaoqian. Review of college students volunteer service over the past ten years, Contemporary education forum, 2012 (2). 